This item was submitted to Loughborough's Research Repository by the author.

Items in Figshare are protected by copyright, with all rights reserved, unless otherwise indicated.

\title{
Experimental study of workpiece-level variability in blind-via electroplating
}

PLEASE CITE THE PUBLISHED VERSION

PUBLISHER

Professional Engineering Publishing / @ IMechE

VERSION

VoR (Version of Record)

LICENCE

CC BY-NC-ND 4.0

REPOSITORY RECORD

Poon, G.K.K., J.S.F. Chan, and David J. Williams. 2019. "Experimental Study of Workpiece-level Variability in Blind-via Electroplating”. figshare. https://hdl.handle.net/2134/4751. 
This item was submitted to Loughborough's Institutional Repository (https://dspace.lboro.ac.uk/) by the author and is made available under the following Creative Commons Licence conditions.

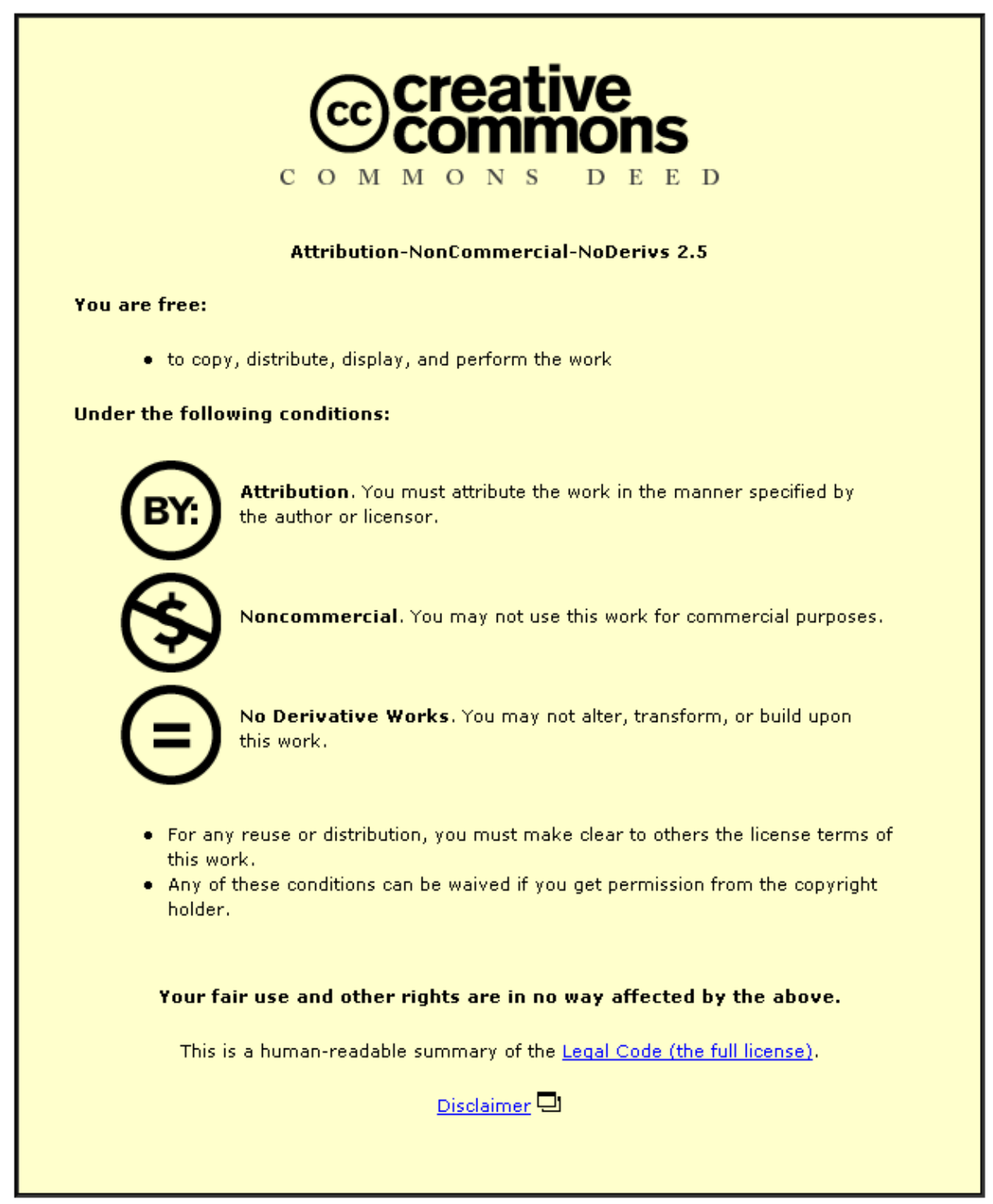

For the full text of this licence, please go to: http://creativecommons.org/licenses/by-nc-nd/2.5/ 


\title{
Experimental study of workpiece-level variability in blind-via electroplating
}

\author{
G K K Poon ${ }^{1 *}$, J S F Chan ${ }^{2}$ and D J Williams ${ }^{3}$
}

${ }^{1}$ Department of Manufacturing Engineering and Engineering Management, City University of Hong Kong, Hong Kong

${ }^{2}$ Engineering Mechanics, Materials and Design, School of Science and Technology, Open University of Hong Kong, Hong Kong

${ }^{3}$ Wolfson School of Mechanical and Manufacturing Engineering, Loughborough University, Loughborough, Leicestershire, UK

\begin{abstract}
The acid copper electroplating process for the manufacture of printed wire boards was studied by statistical techniques. The objectives of this study were to investigate the effects of process and product parameters on the workpiece-level uniformity during the acid copper plating of blind vias and to explore the minimization of the deposit thickness variation. The parameters studied were the concentrations of copper sulphate, sulphuric acid and additive, average current density (ACD), electrode separation (ES), the aspect ratio and the depth ratio of the via holes. Multifactor two-level factorial and the central composite rotatable five-level experiments were designed and conducted sequentially to generate statistical process models. Only the average current density and the electrode separation were found to be significant. A second-order model was then developed for the process in the proximity of the optimum region and verified experimentally to locate the optimum combinations of ACD and ES with respect to minimum thickness variability across the whole workpiece. Post-optimal analysis showed that the optimum solution was more sensitive to the electrode separation than the average current density.
\end{abstract}

Keywords: blind vias, acid copper electroplating, statistical experimentation, variability control

\section{NOTATION}

A

B

C

$\mathrm{D}$

E

F

G

$L$

$R$

$\mathrm{SD}$

$\mathrm{SD}_{\min }$ concentration of sulphuric acid $(\mathrm{g} / \mathrm{l})$

concentration of copper sulphate $(\mathrm{g} / \mathrm{l})$

average current density $\left(\mathrm{mA} / \mathrm{cm}^{2}\right)$

electrode separation $(\mathrm{cm})$

interhole distance $(\mathrm{cm})$

corrected aspect ratio $(\mathrm{mm})$

depth ratio

thickness of a printed circuit board (mm)

radius of a via hole ( $\mathrm{mm})$

standard deviation of plating thickness along

the via hole wall, as predicted by the statistical models $(\mu \mathrm{m})$

minimum standard deviation of plating

thickness along the via hole wall, as predicted by the statistical models $(\mu \mathrm{m})$
The MS was received on 2 June 1999 and was accepted after revision for publication on 17 July 2000.

* Corresponding author: Department of Manufacturing Engineering and Engineering Management, City University of Hong Kong, Tat Chee Avenue, Kowloon Tong, Hong Kong.

\section{INTRODUCTION}

The plated through-hole (PTH) and blind via (BV) are two widely used means of interconnection between the wiring layers of multilayer printed wiring boards (PWBs). In particular, the BV is regarded as the most efficient method of reducing the volume of space consumed by the layer-to-layer interconnects, and its importance is growing with the impending drive toward smaller geometry PWBs and integrated circuit package substrates [1]. The significance of uniform plating thickness of PTHs over the whole workpiece (PWB), discussed by Kessler and Alkire [2], applies equally to the electroplating of BVs. Reviews of previous work in the current distribution modelling of electrodeposition processes $[3,4]$ show that researchers have been concentrating on the feature-level plating uniformity of PTHs, i.e. the thickness distribution along the wall of a particular through-hole (see, for example, references [5] to [7]). Based on fundamental electrochemical principles, these models simulated the effect of various product and process parameters on the current 
distribution under well-defined assumptions and polarization characteristics. However, their proposed solution algorithms using numerical techniques, such as finite element and boundary element methods, are not readily extendable to the workpiece-level thickness distribution, i.e. the distribution of wall thickness among several through-holes over a substrate surface. Little modelling work has been done for the electroplating of BVs, at both the feature and the workpiece level.

On the other hand, the multiparameter nature of the electrodeposition process lends itself to modern methods of experimental design, but little has been published in the literature on this approach to solving problems. Empirical modelling of the through-hole plating process with statistically designed experiments was attempted by some authors, but only at the level of features [8-11], and no similar work was reported for the plating of BVs. Generally, these activities represent successful applications of simple designed experiments to obtain obvious directions of process improvement, usually in the form of a set of recommended factor settings. Empirical modelling and optimization of the process, however, can rarely be achieved and verified in a single set of experimental trials. Different experimental techniques are needed to achieve specific purposes during the stepby-step modelling process. This paper presents how planned matrix experiments, namely fractional factorials and central composite designs, can be conducted sequentially to model empirically the main effects as well as possible interactions of major process parameters on the average plating thickness and its variations in a BV electroplating process. This approach allows the optimal combination of these factors to be systematically obtained to minimize the workpiece-level plating thickness variability within the allowable process windows.

\section{EXPERIMENTAL DETAILS}

A computer numerically controlled (CNC) drilling machine was used to drill the BVs in the test boards using part programs (GM codes) developed with a text editor. Four layouts of the test boards are shown in Fig. 1 to illustrate the combinations of the various levels of interhole distance and the corrected aspect ratio. (The corrected aspect ratio, $L^{2} / R$, suggested in references [2] and [12] to [14] as a better indicator of the difficulty in achieving uniform plating of throughholes, is used here instead of the conventional definition of aspect ratio $L / R$. $L$ is the thickness of the printed circuit board (PCB) and $R$ is the radius of the via hole.) Depending on the dimension of the interhole distance (see Table 1), a maximum of 30 and a minimum of eight BVs were drilled in the test boards.

Before the copper plating process was performed, the non-conductive interior of the BVs was first metallized with a thin film of copper $(\approx 0.5 \mu \mathrm{m})$ by the electroless copper process. Electroless solutions were prepared using analytical grade commercial reagents [15] and deionized water.

The plating bath employed was an acid copper sulphate solution, widely used in the PCB industry, containing copper(II) sulphate $\left(\mathrm{CuSO}_{4} \cdot 5 \mathrm{H}_{2} \mathrm{O}\right)$, sulphuric acid $\left(\mathrm{H}_{2} \mathrm{SO}_{4}\right)$, chloride ions $\left(\mathrm{Cl}^{-}\right)$and brightener (a proprietary organic additive [16]). Copper sulphate was the source of the metal (copper) deposit while the acid enhanced the solution conductivity. Sufficient chloride ions $(60-80 \mathrm{ppm})$ and brightener $(10 \mathrm{ppm})$ were included to give a bright and fine-grained plating. The anodes used were phosphorized copper plates. All the plating was performed in an air-agitated purpose-built testing cell which allowed precise control of the interelectrode separation and bath chemistry. The plating duration
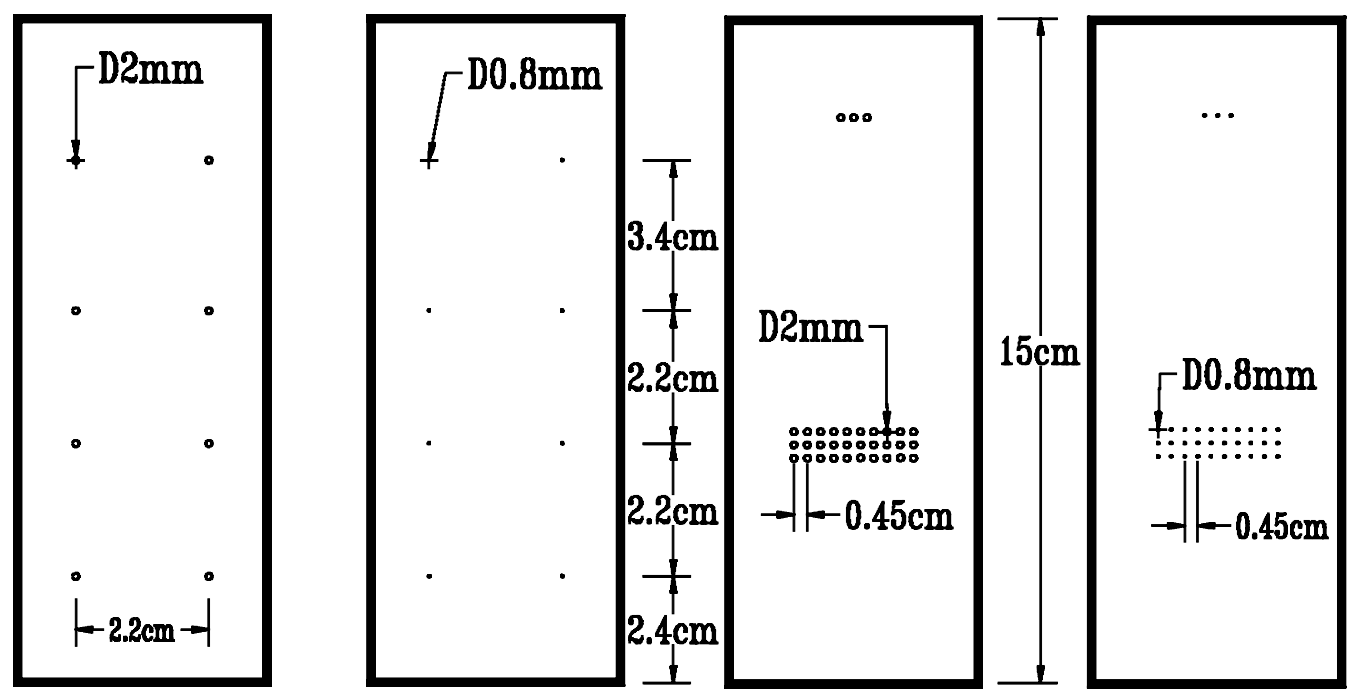

Fig. 1 Test boards of the BV experiments (not to scale) 
was fixed at 20 min for all the experimental runs, after which the deposit thickness along the hole walls was measured by an X-ray coating thickness gauge on sectioning.

The parameters studied in this work included the concentration of copper sulphate, sulphuric acid, average current density, electrode separation, corrected aspect ratio, interhole distance and the depth ratio of the via holes. The experimental strategies and designs are discussed in the next section.

\section{MATRIX DESIGN AND RESULTS ANALYSIS}

\subsection{Experimental strategy}

A sequential experimental strategy was adopted in this research. Two-level fractional factorial design (FFD) [17] was first used to screen out the significant parameters and to obtain first-order models of their effects on the deposit thickness variability. The model indicated the influence of these parameters, and their interactions (if any) on the workpiece-level variability within the process window, as well as the direction of optimizing the performance measure. A five-level central composite design [18] was then used to obtain a second-order model and to construct a response surface for the optimization of the plating process in order to minimize the thickness variability. Two-factor experiments were performed as complements to the factorial designs to verify the adequacy of the model built and to help the interpretation of parameters' effects and the behaviour of the optimum solutions.

\subsection{Factor screening}

Table 1 summarizes the process and product parameters studied in the first stage of experimentation and their
Table 1 Factor settings of the BV screening experiments

\begin{tabular}{llcc}
\hline & & \multicolumn{2}{c}{ Levels } \\
\cline { 3 - 4 } Factors & -1 & +1 \\
\hline A & Concentration of sulphuric acid $(\mathrm{g} / \mathrm{l})$ & 165 & 200 \\
$\mathrm{~B}$ & Concentration of copper sulphate $(\mathrm{g} / \mathrm{l})$ & 65 & 90 \\
$\mathrm{C}$ & Average current density $\left(\mathrm{mA} / \mathrm{cm}^{2}\right)$ & 32.28 & 43.04 \\
$\mathrm{D}$ & Electrode separation $(\mathrm{cm})$ & 12.7 & 17.78 \\
$\mathrm{E}$ & Interhole distance $(\mathrm{cm})$ & 0.45 & 2.2 \\
$\mathrm{~F}$ & Corrected aspect ratio $(\mathrm{mm})$ & 2.56 & 6.40 \\
$\mathrm{G}$ & Depth ratio & 0.33 & 0.67 \\
\hline
\end{tabular}

levels. The ranges of A, B, C and D cover the usual operating window while those of $\mathrm{E}$ and $\mathrm{F}$ represent the limits of the configuration of the purpose-built testing cell and the thickness of the test board.

A 32-run 2 VI FFD [17] was used in the BV screening experiments. This design enabled the simultaneous study of the main effects of all the parameters and their possible interactions in a small number of runs. The resolution VI design was constructed using a $2^{5}$ full factorial as the first five columns and the defining relationship $I=\mathrm{ABCDF}=\mathrm{ABDEG}$ for the last two columns. Such high resolution ensured that each main effect was aliased only with high-order interactions, e.g. three- or fourfactor interactions, which could be assumed to be negligible. The mean and standard deviation (SD) of the plating thickness readings taken for each board were used as the responses. All the hole walls were measured but the largest and smallest thickness values were excluded from the calculations to reduce the bias caused by extreme data. The parameter settings and the responses of the screening experiments, which were conducted in a randomized order, are summarized as Table 2. All the effect calculations and analysis were carried out using JMP Release 3.2 while the halfnormal probability and response surface plots were

Table 2 Parameter settings and the responses of the BV screening experiment

\begin{tabular}{|c|c|c|c|c|c|c|c|c|c|c|c|c|c|c|c|c|c|}
\hline A & B & $\mathrm{C}$ & $\mathrm{D}$ & $\mathrm{E}$ & $\mathrm{F}$ & G & $\begin{array}{l}\text { Mean } \\
(\mu \mathrm{m})\end{array}$ & $\begin{array}{l}\text { SD } \\
(\mu \mathrm{m})\end{array}$ & A & B & $\mathrm{C}$ & $\mathrm{D}$ & $\mathrm{E}$ & $\mathrm{F}$ & $\mathrm{G}$ & $\begin{array}{l}\text { Mean } \\
(\mu \mathrm{m})\end{array}$ & $\begin{array}{l}\text { SD } \\
(\mu \mathrm{m})\end{array}$ \\
\hline- & - & - & - & - & - & + & 8.583 & 1.129 & - & - & - & - & + & - & - & 8.067 & 1.224 \\
\hline+ & - & - & - & - & + & - & 6.800 & 0.985 & + & - & - & - & + & + & + & 6.699 & 1.092 \\
\hline- & + & - & - & - & + & - & 7.278 & 1.347 & - & + & - & - & + & + & + & 7.569 & 1.280 \\
\hline+ & + & - & - & - & - & + & 8.743 & 1.151 & + & + & - & - & + & - & - & 7.884 & 1.381 \\
\hline- & - & + & - & - & + & + & 10.750 & 2.197 & - & - & + & - & + & + & - & 8.595 & 1.859 \\
\hline+ & - & + & - & - & - & - & 10.230 & 1.838 & + & - & + & - & + & - & + & 8.472 & 1.865 \\
\hline- & + & + & - & - & - & - & 7.912 & 1.744 & - & + & + & - & + & - & + & 9.914 & 1.867 \\
\hline+ & + & + & - & - & + & + & 10.660 & 2.101 & + & + & + & - & + & + & - & 8.742 & 2.005 \\
\hline- & - & - & + & - & + & - & 9.292 & 1.760 & - & - & - & + & + & + & + & 8.478 & 1.674 \\
\hline+ & - & - & + & - & - & + & 7.784 & 1.684 & + & - & - & + & + & - & - & 6.843 & 1.215 \\
\hline- & + & - & + & - & - & + & 8.553 & 1.957 & - & + & - & + & + & - & - & 7.464 & 1.275 \\
\hline+ & + & - & + & - & + & - & 9.082 & 1.656 & + & + & - & + & + & + & + & 8.278 & 1.446 \\
\hline- & - & + & + & - & - & - & 11.200 & 2.472 & - & - & + & + & + & - & + & 12.050 & 2.585 \\
\hline+ & - & + & + & - & + & + & 10.920 & 2.147 & + & - & + & + & + & + & - & 10.900 & 2.587 \\
\hline- & + & + & + & - & + & + & 11.910 & 2.142 & - & + & + & + & + & + & - & 11.470 & 2.339 \\
\hline+ & + & + & + & - & - & - & 11.240 & 2.423 & + & + & + & + & + & - & + & 13.050 & 2.629 \\
\hline
\end{tabular}




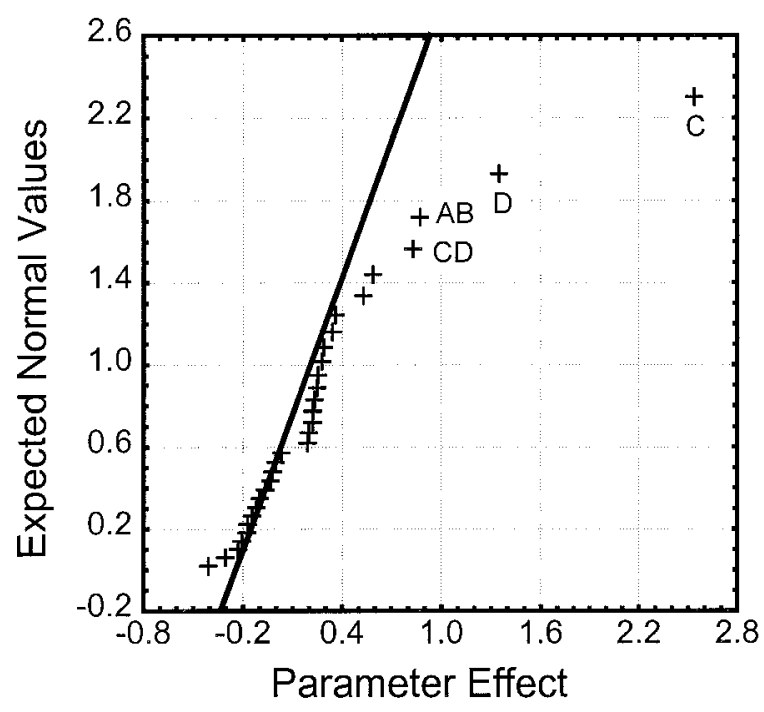

(a) Half-normal Probability Plot

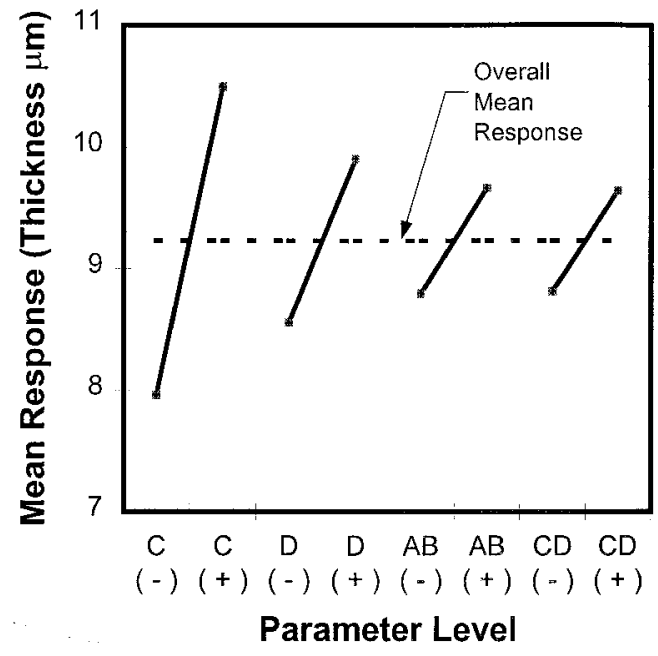

(b) Analysis of Mean Plot

Fig. 2 Effect plots of the BV screening experiment (mean responses)

constructed by STATISTICA Release 5.0 and MATLAB Release 4.2.

\subsection{Analysis of the mean response}

The half-normal probability plot [19] of the mean responses, Fig. 2a, shows that the significant parameters are the average current density (C), electrode separation (D) and the two two-factor interactions: sulphuric acid $\times$ copper sulphate $(\mathrm{AB})$ and average current density $\times$ electrode separation (CD). An ANOVA test confirmed also their significance $(\alpha<0.005)$. Figure $2 \mathrm{~b}$ illustrates the strong positive effects of $\mathrm{C}, \mathrm{D}, \mathrm{AB}$ and $\mathrm{CD}$ on the mean plating thickness of the BVs and the corresponding interaction plots are given in Fig. 3.

The mean response reflects the average plating rate under the particular plating condition. Figure 3 a shows that maximum average plating rate can be achieved when the concentrations of both sulphuric acid (A) and copper sulphate (B) are at their high (+) level, i.e. 200 and $90 \mathrm{~g} / \mathrm{l}$ respectively. However, this maximum plating rate is found to be not significantly different from that obtained when both A and B are at their low (-) level, i.e. 165 and $65 \mathrm{~g} / 1$ respectively. This suggests that when the ratio between the concentrations of the sulphuric acid and the copper sulphate is maintained in the range $2.2-2.5$ (the value 2.2 represents the ratio of the concentration of sulphuric acid to that of the copper sulphate when both of them are at the high (+) level, i.e. 200/90, while the value 2.5 represents the same ratio when both of them are at the low (-) level, i.e. 165/65), the maximum plating rate can be achieved regardless of their absolute concentration levels, provided, of course, that they are within their respective operating ranges. Therefore, alternating the levels of either one of the parameters without a proportional change of the other one will result in a lower average plating rate. On the other hand, Fig. $3 \mathrm{~b}$ shows that maximum average plating rate results when high average current density $\left(43.04 \mathrm{~mA} / \mathrm{cm}^{2}\right)$ and large electrode separation $(17.78 \mathrm{~cm})$ are employed. While the first condition is common to all Faradaic reactions, the interaction plot shows that this Faradaic effect is attenuated by the magnitude of the electrode separation, which manifests itself as the strong interaction between the two parameters.

\subsection{First-order process model of SD responses}

The half-normal probability plot of Fig. 4 shows that the average current density (C) and the electrode separation (D) are the only two active parameters affecting the workpiece-level uniformity of the BVs. Both of the two parameters have strong positive effect on the thickness variation, as illustrated in the effect plots of Fig. 5, which means that minimum variability results when both of them are at their low level, i.e. $32.28 \mathrm{~mA} / \mathrm{cm}^{2}$ and $12.7 \mathrm{~cm}$ respectively. A first-order model was built for the $\mathrm{BV}$ process using the significant parameters identified above, with the ANOVA tests performed by pooling the residual sum of squares to give an estimate of the random errors for the experiments. The threeterm BV model $(\alpha<0.0001)$ is found to be highly significant and given by the following equation in coded form:

$$
\mathrm{SD}=1.7830+0.3920 \mathrm{C}+0.2165 \mathrm{D}
$$

where SD is the predicted standard deviation and $\mathrm{C}$ and $\mathrm{D}$ take the values -1 or +1 for the low and high levels of the corresponding parameters. Analysis of the residuals 


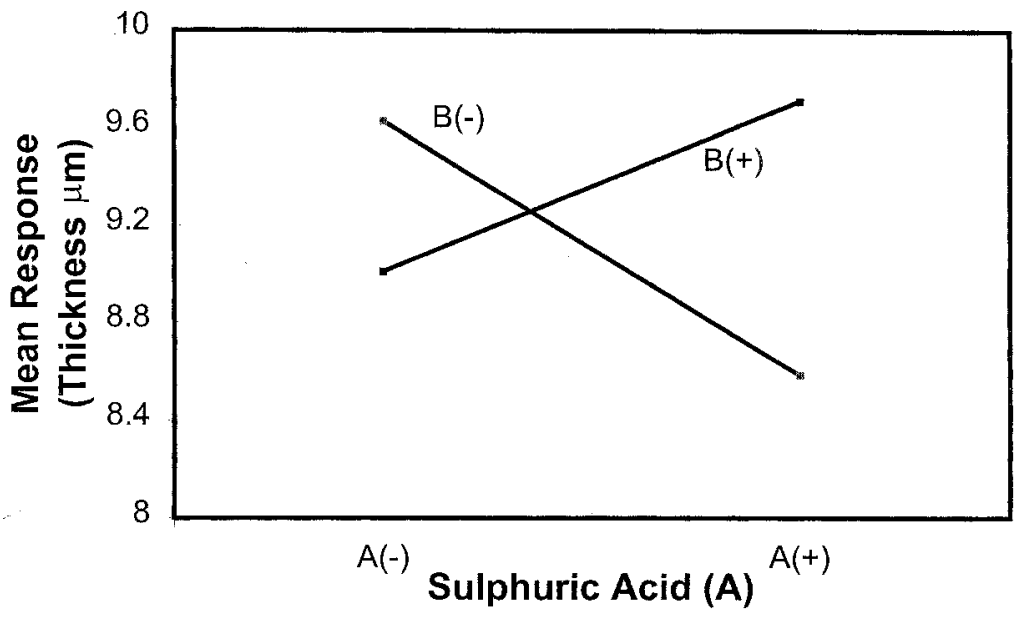

(a) AB Interaction

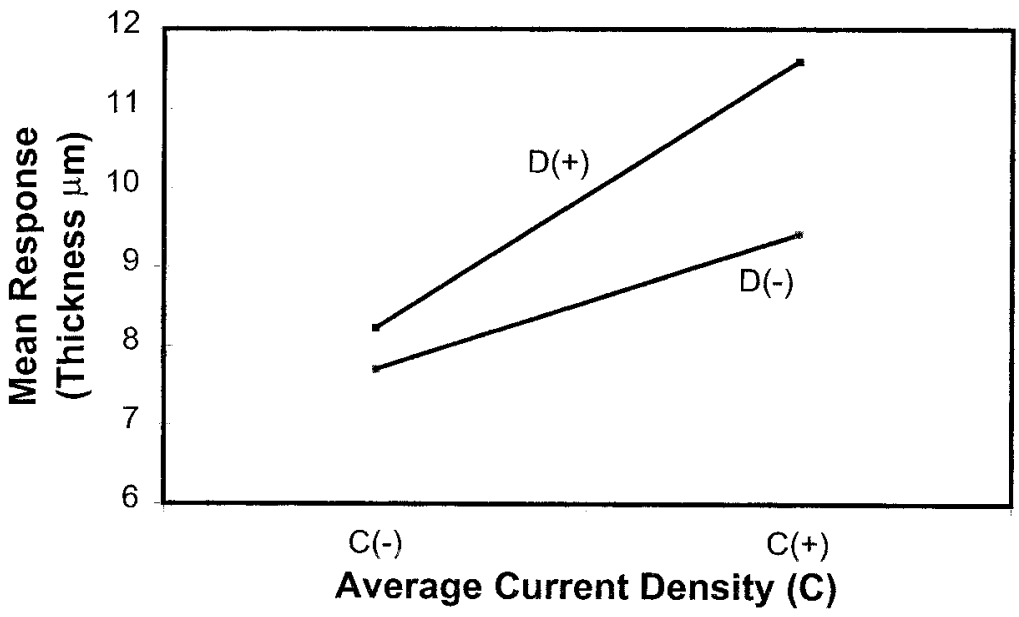

(b) CD Interaction

Fig. 3 Interaction plots for the parameters A, B, C and D for the mean responses

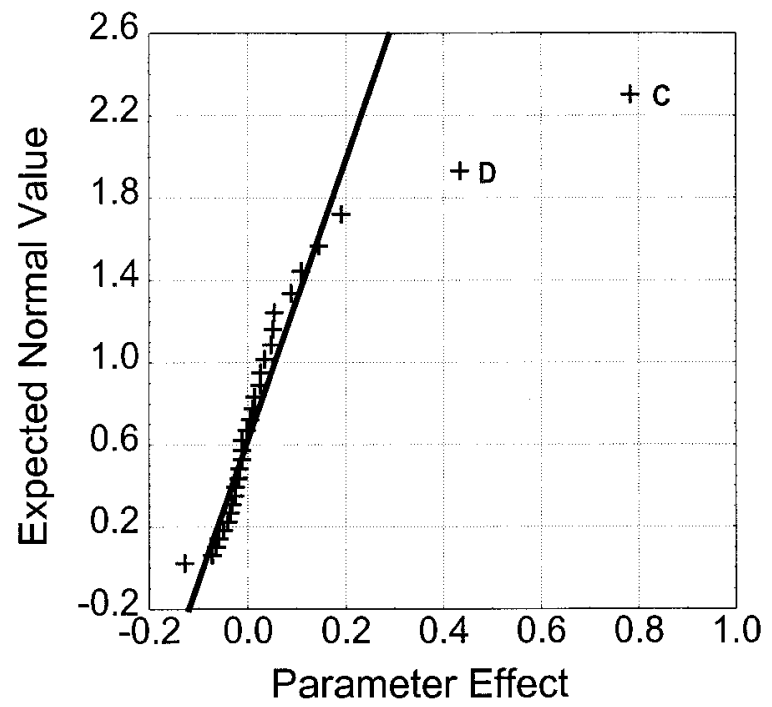

Fig. 4 Half-normal probability plot of the BV screening experiment (SD responses)

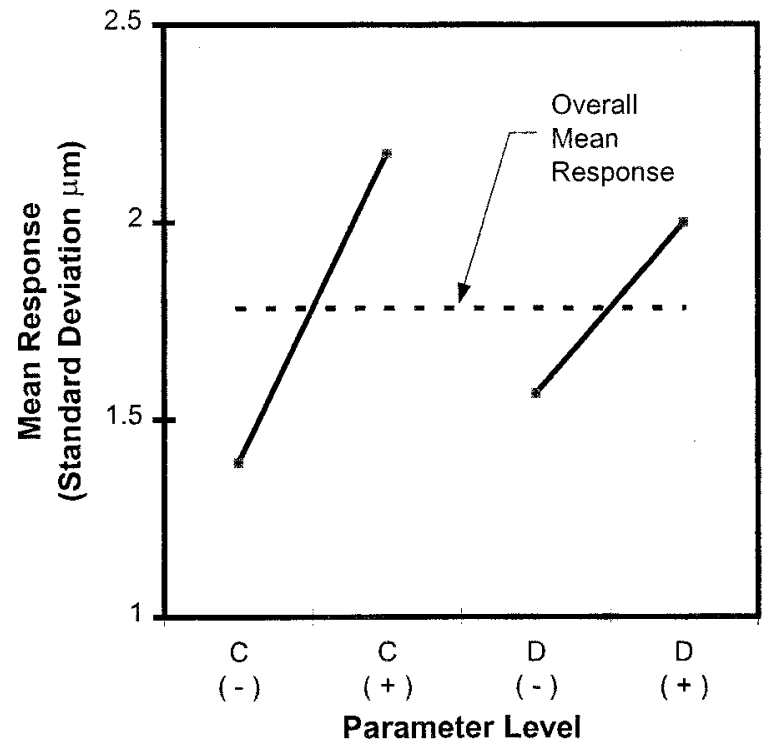

Fig. 5 Analysis of mean plot for the SD responses 


\section{BV 3-term First-order Model}

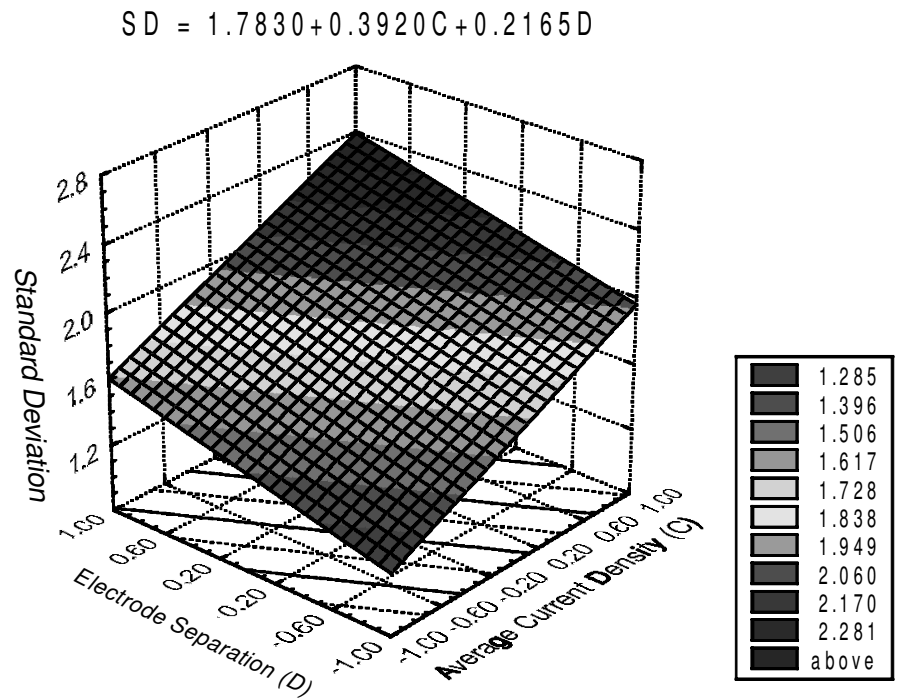

Fig. 6 Response surface and contour plot of the BV three-term first-order model

of the first-order model revealed no abnormality of concern. The lack of fit, which is found to be insignificant ( $\alpha=0.469$ ), shows that the first-order models accurately describe the response surface and can be used to search for levels of the parameters that would produce more optimal values of the response, i.e. smaller thickness variation (SD). The response surface of the first-order model is shown in Fig. 6, which indicates clearly the location of minimum variability, $[C(-), D(-)]$, within the experimental range. This corner represents also the approximate location of the centre point of the CCD design for the second-order model building.

\subsection{Second-order model building}

Four more experiments were performed in the proximity of the minimum variability, $[\mathrm{C}(-), \mathrm{D}(-)]$, identified in the first-order model above. The factor settings and responses are summarized in Table 3 . All the other insignificant parameters were held constant at their low $(-)$ levels. The same measurement and response scheme was adopted in this round of experiments and the average plating efficiency was found to be 87.3 per cent.
Table 3 Design points and responses in the proximity of $[\mathrm{C}(-), \mathrm{D}(-)]$

\begin{tabular}{llll}
\hline Board & $\begin{array}{l}\text { Average current } \\
\text { density }\left(\mathrm{mA} / \mathrm{cm}^{2}\right)\end{array}$ & $\begin{array}{l}\text { Electrode } \\
\text { separation }(\mathrm{cm})\end{array}$ & $\begin{array}{l}\text { Standard } \\
\text { deviation }(\mu \mathrm{m})\end{array}$ \\
\hline 1 & 35.5 & 14.0 & 1.103 \\
2 & 32.3 & 14.0 & 0.894 \\
3 & 34.4 & 13.3 & 0.820 \\
4 & 32.3 & 12.7 & 0.953 \\
\hline
\end{tabular}

The results show that further reduction of thickness variation can be achieved within the region and the combination of $\mathrm{C}=35.0 \mathrm{~mA} / \mathrm{cm}^{2}$ and $\mathrm{D}=14.0 \mathrm{~cm}$ was selected as the centre point of the central composite design for second-order model building.

Using the centre point identified above, a 10-run rotatable central composite design [17] involving the parameters $\mathrm{C}$ and $\mathrm{D}$ was designed and conducted to build a second-order model for the workpiece-level variation. Table 4 summarizes the factor levels and setting of the central composite design employed.

The standard deviations of the hole-wall plating thickness were taken as the responses and are

Table 4 Factor levels and settings of the BV CCD experiment

\begin{tabular}{|c|c|c|c|c|c|c|c|}
\hline \multirow{2}{*}{\multicolumn{2}{|c|}{ Factors }} & \multirow{3}{*}{$\begin{array}{l}\text { Fixed level } \\
180\end{array}$} & \multicolumn{5}{|c|}{ Factor levels } \\
\hline & & & \multirow{2}{*}{$\frac{-1.414}{-}$} & \multirow{2}{*}{$\frac{-1}{-}$} & \multirow{2}{*}{$\begin{array}{l}0 \\
- \\
\end{array}$} & \multirow{2}{*}{$\frac{+1}{-}$} & \multirow{2}{*}{$\frac{1.414}{-}$} \\
\hline A & Sulphuric acid $(\mathrm{g} / \mathrm{l})$ & & & & & & \\
\hline B & Copper sulphate $(\mathrm{g} / \mathrm{l})$ & 75 & - & - & - & - & - \\
\hline $\mathrm{C}$ & Average current density $\left(\mathrm{mA} / \mathrm{cm}^{2}\right)$ & - & 31.2 & 32.3 & 35.0 & 37.7 & 38.8 \\
\hline $\mathrm{D}$ & Electrode separation $(\mathrm{cm})$ & - & 12.2 & 12.7 & 14.0 & 15.2 & 15.8 \\
\hline $\mathrm{E}$ & Interhole distance $(\mathrm{cm})$ & 0.45 & - & - & - & - & - \\
\hline $\mathrm{F}$ & Corrected aspect ratio $(\mathrm{mm})$ & - & - & - & - & - & - \\
\hline G & Depth ratio & 0.875 & - & - & - & - & - \\
\hline
\end{tabular}


Table 5 Factor levels and responses of the BV CCD experiment

\begin{tabular}{llrlllll}
\hline Observation & $\mathrm{C}$ & $\mathrm{D}$ & $\mathrm{SD}(\mu \mathrm{m})$ & Observation & $\mathrm{C}$ & $\mathrm{D}$ & $\mathrm{SD}(\mu \mathrm{m})$ \\
\hline 1 & -1 & -1 & 2.386 & 6 & 1.414 & 0 & 1.168 \\
2 & 1 & -1 & 1.022 & 7 & 0 & -1.414 & 2.815 \\
3 & -1 & 1 & 2.314 & 8 & 0 & 1.414 & 3.425 \\
4 & 1 & 1 & 3.165 & 9 & 0 & 0 & 1.554 \\
5 & -1.414 & 0 & 1.362 & 10 & 0 & 0 & 1.760 \\
\hline
\end{tabular}

summarized in Table 5. Twenty thickness readings were taken from the 10 vias of each test board and the largest and smallest readings were discarded in the calculation. An average plating efficiency of 84.5 per cent was recorded in this round.

The six-term full second order model in coded form is

$$
\begin{aligned}
\mathrm{SD}= & 1.6573-0.0982 \mathrm{C}+0.3667 \mathrm{D}-0.1887 \mathrm{C}^{2} \\
& +0.7386 \mathrm{D}^{2}+0.5537 \mathrm{CD}
\end{aligned}
$$

The ANOVA test confirmed the significance of the model $(\alpha=0.0045)$; its $R_{\mathrm{A}}^{2}(0.9266)$ performance is better than that of the first-order model derived above although its $R_{\text {prediction }}^{2}(0.7781)$ is slightly lower. The full model is also the best-fitted model under the backward elimination process [20] and Mallow's criteria [21]. Residual analysis of the model revealed no abnormality of concern. Figure 7 shows that the response surface of the second-order mode is a saddle system [18], in which the stationary point is neither a maximum nor a minimum point.

The location of the minimum variation within the experimental space can be found on the plane of $\mathrm{C}=1.414$, on which the second-order model becomes

$$
\mathrm{SD}=0.7386 \mathrm{D}^{2}+1.1496 \mathrm{D}+1.1410
$$

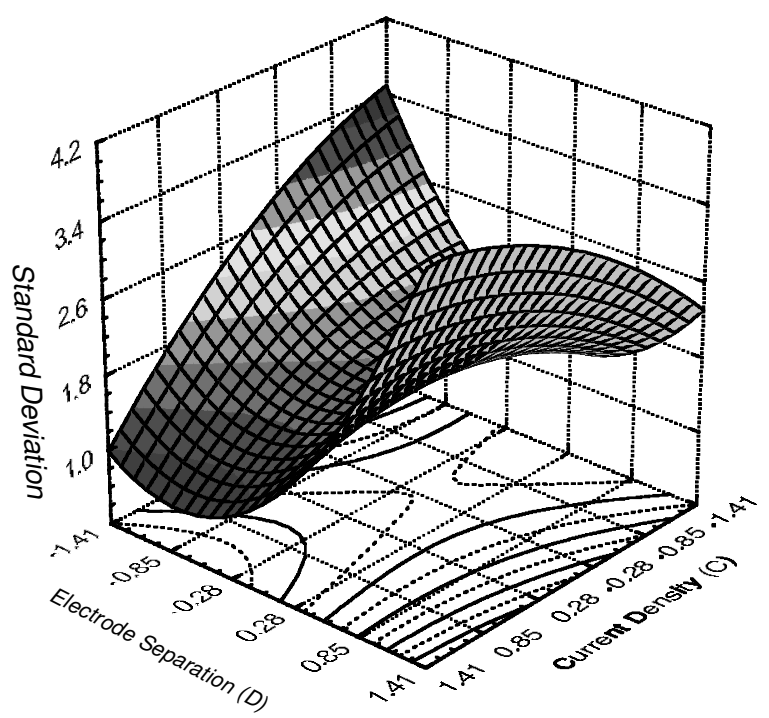

Fig. 7 Response surface and contour plot of the locus of $\mathrm{SD}_{\text {min }}$ within the optimum region
Differentiating equation (3) with respect to D yields the stationary point of $\mathrm{C}=1.414\left(36 \mathrm{~mA} / \mathrm{cm}^{2}\right)$ and $\mathrm{D}=-0.7782(12.98 \mathrm{~cm})$, which gives a minimum standard deviation, $\mathrm{SD}_{\min }$, of $0.6934 \mu \mathrm{m}$. The locus of the minimum standard deviation is given in Fig. 8 while Figs $9 \mathrm{a}$ and $\mathrm{b}$ show respectively the quadratic relationship between $\mathrm{SD}_{\min }$ and $\mathrm{C}$ and the linear relationship between the optimum values of $\mathrm{C}$ and $\mathrm{D}$. Figures 8 and 9 a show that $\mathrm{SD}_{\min }$ is smaller at the two extreme values of C. Figure $9 \mathrm{~b}$ shows that the sensitivity of the optimum solution to the electrode separation is 2.7 times higher than to the average current density. Physically, this means that, as long as the process is operating along the path shown in Fig. 9b, the workpiece-level variability of the BVs will be minimized with respect to that particular combination of average current density and electrode separation, and in all cases is limited to the range $0.7-$ $1.7 \mu \mathrm{m}$. These correspond to a 29-71 per cent reduction of variability when compared with the worst scenario $(2.4 \mu \mathrm{m})$ of the first-order response surface (Fig. 6).

\subsection{Model verification}

Twenty-four more experiments were performed to verify the adequacy of the second-order model in predicting the workpiece-level plating uniformity within the experimental range. The standard deviation of 20 hole-wall plating thickness readings was determined from each test board.

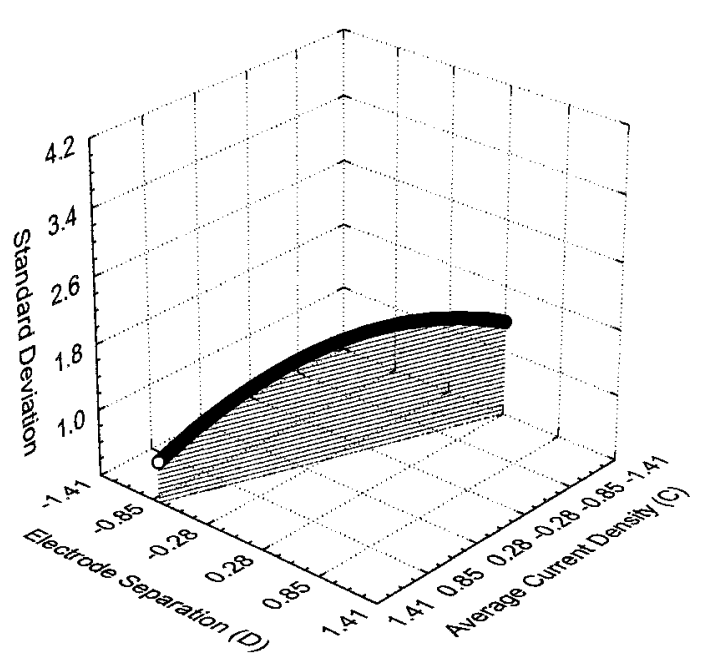

Fig. 8 BV full second-order model 


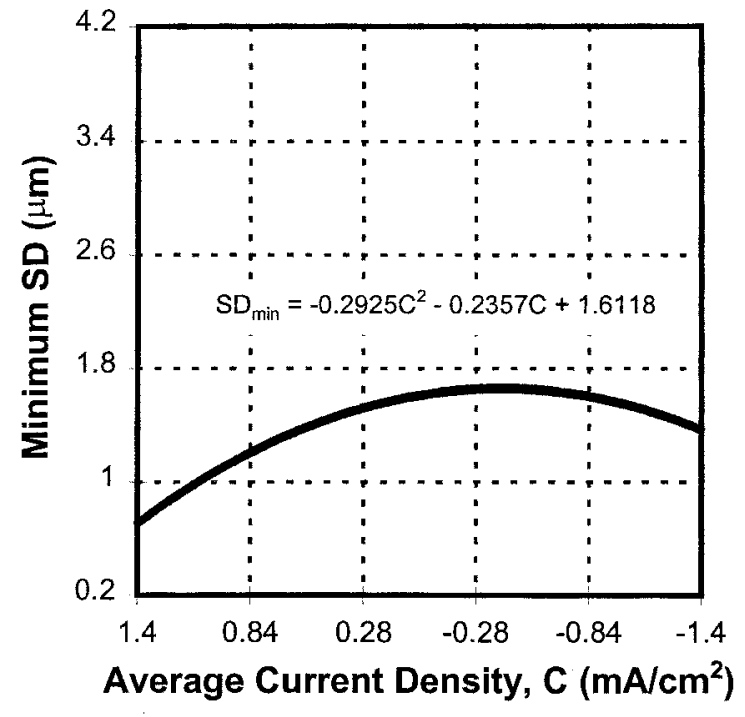

(a)

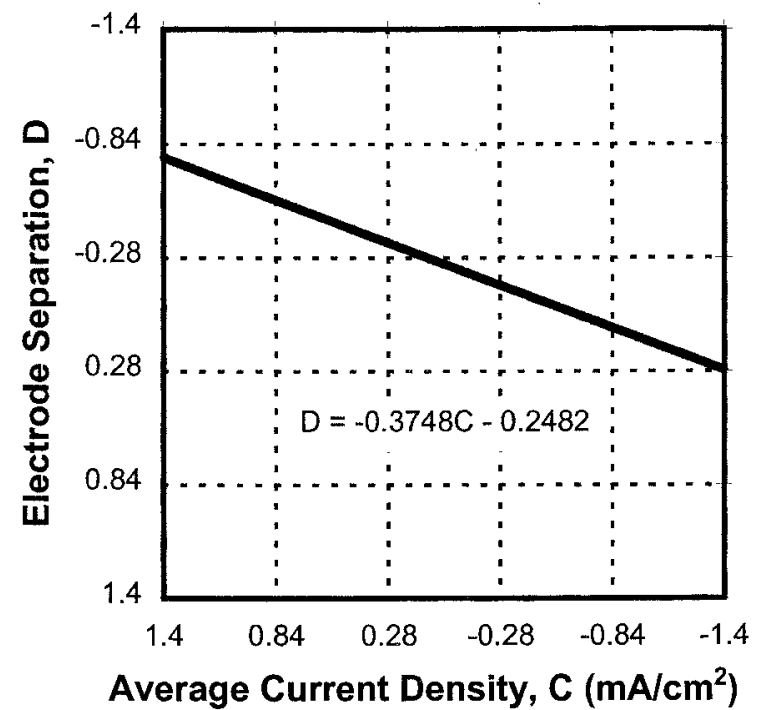

(b)

Fig. 9 (a) Relationship between $\mathrm{SD}_{\text {min }}$ and the average current density. (b) Locus of the optimum combination of parameters $\mathrm{C}$ and $\mathrm{D}$

Table 6 Factor settings and responses of the BV verification experiment

\begin{tabular}{llll}
\hline \multirow{2}{*}{$\begin{array}{l}\text { Electrode } \\
\text { separation }(\mathrm{cm})\end{array}$} & $\begin{array}{l}\text { Average current } \\
\text { density }\left(\mathrm{mA} / \mathrm{cm}^{2}\right)\end{array}$ & Actual & Predicted \\
\cline { 3 - 4 } 12.7 & 31.0 & 2.3699 & 2.3525 \\
& 32.0 & 2.0194 & 2.1521 \\
14.0 & 35.5 & 1.2117 & 0.9751 \\
& 30.0 & 1.2637 & 1.5668 \\
& 33.0 & 1.7062 & 1.6301 \\
15.2 & 34.0 & 1.4435 & 1.5304 \\
& 35.0 & 1.1713 & 1.3703 \\
& 30.5 & 2.3076 & 2.2775 \\
& 31.5 & 2.5554 & 2.5503 \\
& 34.0 & 2.8616 & 2.9680 \\
& 37.0 & 3.1164 & 2.9710 \\
& 39.0 & 2.8862 & 2.6710 \\
\hline
\end{tabular}

Two replicates were run for each of the twelve combinations of C and D, while the mean SDs were taken as the responses. The factor settings and responses are summarized in Table 6. Predicted responses of the second-order model [equation (2)] are plotted against the actual standard deviations obtained from the model building (Table 5) and verification runs (Table 6) in Fig. 10. It shows that the full second-order model is able to predict 92.6 per cent of the variations, which is much higher than the expected performance of 77.81 per cent suggested by $R_{\text {prediction }}^{2}$ of the model determined in Section 3.5.

\section{DISCUSSION}

Previous work on the modelling of PTH plating shows that the feature scale uniformity is limited by the ohmic resistance (secondary current density effect) rather than the mass transfer resistance (cupric ion concentration, agitation effect) of the system $[\mathbf{6}, \mathbf{1 4}, \mathbf{2 2}]$. Similar results are not found in the literature for BV plating. The statistical models developed here show that the ohmic limitation applies also to the workpiece-level thickness variation for BV plating, although the mass transfer limitation has more influence on optimum BV plating than the PTH plating, as reflected in the mean response analysis of Section 3.3.

The electrode separation was found to be significant in affecting the workpiece-level variation of the BVs, and the uniformity deteriorated with the electrode separation. This is evident from both the first- and the second-order models, equations (1) and (2) respectively, of the process. It is believed that, under the same agitation scheme, the convective flow of electrolyte into the BVs is enhanced when the electrode separation is reduced and hence the deposit uniformity is improved. The first-order model shows also that the workpiece-level variability is minimized when both the average current density and the electrode separation are at their low levels. Such a combination, however, will result in a lower average plating rate (Fig. 3b). Analysis of the mean thickness responses of the screening experiments shows that the interaction effect between the sulphuric acid and copper sulphate (AB) was significant in affecting the average plating rate. The plating rate was maximized when a high acid concentration was coupled with a high sulphate concentration, or its reverse, as shown in Fig. 3a. This can be explained by the fact that addition of copper sulphate has a negative effect on the acidity and hence the conductivity of the acid-sulphate system [23], while conductivity has a negative effect on the reaction rate of plating without convection [24], with which the BV plating process is comparable. Therefore, the negative effect of the acid 


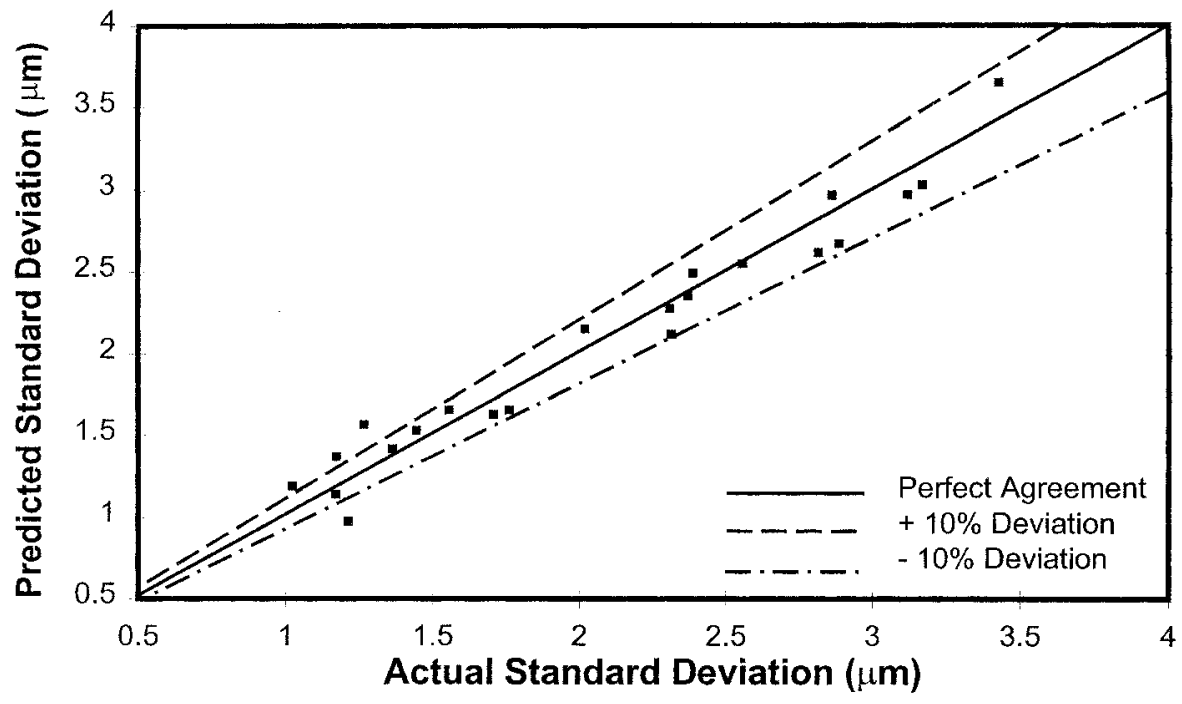

Fig. 10 Verification results of the BV full second-order model

on the plating rate was counterbalanced by the copper sulphate when these two components were in appropriate proportion. Such an interaction effect, which does not affect the thickness variation, could be used to obtain a compromise between the two conflicting requirements of minimum workpiece-level variability and high average plating rate.

\section{CONCLUSION}

This paper summarizes the sequential experimental studies of the BV copper plating process. Significant process parameters affecting the workpiece-level uniformity were identified as the average current density and the electrode separation. Statistically proven and electrochemically informed models were developed for the copper plating of $\mathrm{BVs}$ to predict and minimize, within the operability range and experimental accuracy, the workpiece-level thickness variability. As these models are defined by parameters independent of the physiochemical and polarization properties of the electrolytic system, they can be used for the variability control and optimization of industrial BV plating processes.

\section{REFERENCES}

1 Weinhold, M. and Powell, D. J. High speed laser ablation of microvia holes in non-woven Aramid reinforced printed wiring boards to reduce cost. Circuit World, 1996, 22(3), 16-22.

2 Kessler, T. and Alkire, R. Copper plating of multilayer printed wiring boards. Plating Surf. Finishing, September 1976, 63(9), 22-27.

3 Dukovic, J. O. Computation of current distribution in electrodeposition, a review. IBM J. Res. Dev., 1990, 34(5), 693-705.
4 Poon, G. K. K. and Williams, D. J. Modelling of acid copper electroplating: a review. J. Electronics Mfg, March 1998, 8(1), 15-37.

5 Middleman, S. Factors that affect uniformity of plating of through-holes in printed circuit boards II. Periodic flow reversal through the holes. J. Electrochem. Soc., March 1986, 133(3), 492-496.

6 Yung, E. K. and Romankiw, L. T. Fundamental study of acid copper through-hole electroplating process. J. Electrochem. Soc., March 1989, 136(3), 756-767.

7 Chern, J. W. E. and Cheh, H. Y. Modeling of plated through-hole processes. I. Current distribution. J. Electrochem. Soc., October 1996, 143(10), 3139-3144.

8 Barringer, T. and Carano, M. Optimization of an acid copper plating bath for through-hole plating. Plating Surf. Finishing, 1986, 73(3), 36-37.

9 Haluzan, I. and Reichenbach, D. Investigation of copper deposition on printed circuit boards using Taguchi methods. Circuit World, 1991, 17(4), 24-26.

10 Forrest, G. and Reed, D. Current density effect. Print. Circuit Fabrication, 1993, 16(8), 26-30.

11 Bokisa, G. S. and McFarland, C. W. Statistical modelling of printed circuit hole plating. In Proceedings of the 80th AESF Annual Technical Conference, 1993, pp. 1033-1045.

12 Alkire, R. and Mirarefi, A. A. Current distribution in tubular electrodes under laminar flow: one electrode reaction. J. Electrochem. Soc., July 1977, 124(7), 1043-1049.

13 Alkire, R. and Mirarefi, A. A. Current distribution in tubular electrodes under laminar flow: two electrode reactions. J. Electrochem. Soc., August 1977, 124(8), 1214-1220.

14 Yung, E. K., Romankiw, T. L. and Alkire, R. C. Plating of copper into through-holes and vias. J. Electrochem. Soc., January 1989, 136(1), 206-215.

15 Alfachimici. Technical Bulletins 8506 (Cuprolite X-84), 8510 (Microincide 1207), 8200 (Uniphase MLX A), 8501 (Uniphase MLX A+B), 8508 (Drag-Stop 79), 1985.

16 LeaRonal. Technical Bulletin TS 30029-E: Copper Gleam PCM Plus, August 1990.

17 Box, G. P. E., Hunter, W. G. and Hunter, J. S. Statistics for Experimenters, 1978, pp. 306-342, 510-539 (John Wiley, New York). 
18 Myers, R. H. and Montgomery, D. G. Response Surface Methodology: Process and Product Optimization Using Designed Experiments, 1995, pp. 640-655 (John Wiley, New York).

19 Daniel, C. Use of half-normal plots in interpreting factorial two-level experiments. Technometrics, 1959, 1, 311-314.

20 Miller, A. J. Subset Selection in Regression, 1990 (Chapman and Hall, London).

21 Mallows, C. L. Some comments on $C_{\mathrm{p}}$. Technometrics, $1973,15,661-675$.
22 Lanzi, O. and Landau, U. Analysis of mass transport and ohmic limitations in through-hole plating. J. Electrochem. Soc., August 1988, 135(8), 1922-1930.

23 Newman, J. S. Electrochemical Systems, 2nd edition, 1991, pp. 410-415 (Prentice-Hall, Englewood Cliffs, New Jersey).

24 Hazlebeck, D. A. and Talbot, J. B. Modeling of additive effects on the electro-plating of a through-hole. Am. Inst. Chem. Engrs J., 1990, 36(8), 1145-1155. 